This document is the accepted manuscript version of a published work that appeared in final form after peer review and technical editing by the publisher. To access the final edited and published work see link to "View at Publisher (DOI)" at the DORA Empa web page (https://www.dora.lib4ri.ch/empa/).

\title{
The Surface Chemistry of Hydrophobic Silica Aerogels
}

Wim J. Malfait ${ }^{\dagger}{ }^{\star}$, Shanyu Zhao ${ }^{\dagger}$, Rene Verel ${ }^{\ddagger}$, Subramaniam Iswar ${ }^{\dagger}$, Daniel Rentsch ${ }^{\S}$, Resul Fener ${ }^{\#}$, Yucheng Zhang ${ }^{\circ}$, Barbara Milow* and Matthias M. Koebel ${ }^{\dagger} \star$

${ }^{+}$Laboratory for Building Energy Materials and Components, Swiss Federal Laboratories for Materials Science and Technology, Empa, Überlandstrasse 129, CH 8600 Dübendorf, Switzerland, * Corresponding authors: wim.malfait@empa.ch, matthias.koebel@empa.ch

"Laboratory for Inorganic Chemistry, Department of Chemistry and Applied Biosciences, ETH Zurich, Vladimir-Prelog-Weg 1-5/10, CH 8093 Zurich, Switzerland

sLaboratory for Functional Polymers, Swiss Federal Laboratories for Materials Science and Technology, Empa, Überlandstrasse 129, CH 8600 Dübendorf, Switzerland

\#Institute of Materials Research, German Aerospace Center, DLR, 51170 Cologne, Germany

'Electron Microscopy Center, Swiss Federal Laboratories for Materials Science and Technology, Empa, Überlandstrasse 129, CH 8600 Dübendorf, Switzerland 
ABSTRACT: The properties of silica aerogels, and the ability to prepare them by ambient pressure drying, hinge on their chemical surface modification. Until now, quantitative analysis of the surface chemistry has not been possible by state-of-the-art analytical methods. Here, we determine the surface chemistry of six archetypal, ambient pressure dried, hydrophobic silica aerogels and openporous foams with quantitative ${ }^{1} \mathrm{H}^{13} \mathrm{C}$ and ${ }^{29} \mathrm{Si}$ and ${ }^{1} \mathrm{H}_{-}{ }^{29} \mathrm{Si}$ heteronuclear solid-state NMR spectroscopy. The quality of the external calibration, the validation by elemental analysis and the consistency between the ${ }^{1} \mathrm{H},{ }^{13} \mathrm{C}$ and ${ }^{29} \mathrm{Si}$ MAS NMR data, enable us to robustly quantify the surface chemistry of these classical silica materials. Four aerogels were derived from tetraethoxysilane (TEOS), polyethoxydisiloxane (PEDS) or waterglass precursors and hydrophobized with trimethylsilyl (TMS) groups through immersion in hexamethyldisilazane (HMDZ) in heptane, trimethylchlorosilane (TMCS) in heptane, or hexamethyldisiloxane (HMDSO) in ethanol. The resulting aerogels display remarkably similar chemistries despite their very different precursors (alkoxides, waterglass), hydrophobization agents (HMDZ, TMCS, HMDSO) and gelation and hydrophobization solvents (water, ethanol, heptane). The TMS content is nearly the same (22-27 wt\%), the ethoxy content is low $(<4 \mathrm{wt} \%)$ and the silica speciation displays a narrow range for all four aerogels. The ${ }^{1} \mathrm{H}_{-}{ }^{29} \mathrm{Si}$ heteronuclear correlation spectra provide unambiguous evidence for the grafting of the TMS groups on the silica surfaces. Remarkably, the NMR data enables the prediction of the silica particle size to within 1 to $2 \mathrm{~nm}$ of that derived by TEM analysis. Two additional, inherently hydrophobic, ambient pressure dried, open-porous silica foams were synthesized from methyltrimethoxysilane (MTMS) and from a MTMSdimethyldimethoxysilane (DMDMS) mixture, respectively. The reduction in the number of bridging oxygen per Si atom, from 3.76-3.90 for TEOS, PEDS or waterglass based aerogels, to 2.86 for the MTMS based open-porous foam and to 1.90 for the MTMS-DMDMS derived open-porous foam, results in a brittle to super-flexible transition. Our results highlight the importance of the chemical treatment of the wet gels (hydrophobization and solvent exchange) on the final surface chemistry of silica aerogels. 


\section{INTRODUCTION}

Since their first realization in 1932 by Kistler ${ }^{1}$, silica aerogels have been used for thermal insulation ${ }^{2,3}$, catalyst support ${ }^{4}$, selective gas sorption $\left(\mathrm{CO}_{2}\right)^{5-7}$, drug delivery ${ }^{8}$ and oil spill clean-up ${ }^{9}$. These applications depend on the exceptional properties of silica aerogel, most notably their high volume fraction of mesopores and large surface area. However, it is difficult to maintain the porosity during solvent removal because of the strong capillary forces and the condensation reactions between surface silanol groups that occur during drying. To circumvent these problems, silica aerogels traditionally have been prepared by super-critical drying, often after a solvent exchange into $\mathrm{CO}_{2}{ }^{10,11}$. Following the demonstration that the solvent can be removed by evaporative drying at ambient pressure if the surfaces have been hydrophobized, a wide range of synthesis routes have been developed to prepare hydrophobic silica aerogel by ambient pressure drying ${ }^{12-15}$. Classical mesoporous silica aerogels are prepared from waterglass, tetra(m)ethoxysilane (TMOS/TEOS) or polyethoxydisiloxane (PEDS - a prepolymerized form of TEOS) precursors ${ }^{14,16-20}$. Acid-base catalyzed sol-gel processes ${ }^{21}$ produce gels that, when dried without surface modification, are inherently hydrophilic. In order to allow for drying at ambient pressure, and to improve the long-term stability of the final product, the surface can be hydrophobized prior to drying by immersing them in a modification solution where surface silanol groups are replaced by hydrophobic groups, typically trimethylsilyl (TMS). The TMS groups are most often introduced through trimethylchlorosilane (TMCS), hexamethyldisilazane (HMDZ) or hexamethyldisiloxane (HMDSO) hydrophobization agents. An alternative, more direct route to synthesize open-porous, inherently hydrophobic silica materials is to use precursors that already contain chemically bound hydrophobic groups, for example methyltri(m)ethoxysilane (MTMS/MTES) ${ }^{12,}$ ${ }^{22}$ or dimethyldimethoxysilane (DMDMS) ${ }^{23}$ with three or two $\mathrm{Si}-\mathrm{O}$ bonds and one or two $\mathrm{Si}-\mathrm{C}$ bonds, respectively. The resulting materials are super-hydrophobic and flexible ${ }^{12,22,23}$, but the ambient pressure dried flexible foams do not possess the exceptionally low thermal conductivities of classical silica aeorgels due to their larger pore sizes. 
Although ambient pressure drying of hydrophobic silica aerogels is a scientifically and industrially wellestablished process today, the surface modification process has so far eluded quantitative analysis. Solid-state NMR spectroscopy provides element specific and potentially quantitative insights into the speciation and surface chemistry of silica nanomaterials ${ }^{24-32} \cdot{ }^{1} \mathrm{H},{ }^{13} \mathrm{C}$ and ${ }^{29} \mathrm{Si}$ are all spin-1/2 nuclei with well resolved spectra and speciation data can be readily obtained for all major constituents of silica aerogel, apart from oxygen. Recently, we established ${ }^{1} \mathrm{H},{ }^{13} \mathrm{C}$ and ${ }^{29} \mathrm{Si}$ solid-state MAS NMR spectroscopy as an accurate, quantitative method to determine the surface density of various functional groups, e.g. TMS and ethoxy ${ }^{33}$. Here, we use this protocol to compare the surface chemistry and microstructure of six archetypal, ambient-pressure dried, hydrophobic silica aerogels and openporous foams derived from TEOS, PEDS, waterglass, MTMS and DMDMS precursors and quantify the surface composition and spatial density of the different functional groups. In addition, we probe the connectivity of these functional groups to the silica network by ${ }^{1} \mathrm{H}-{ }^{29} \mathrm{Si}$ Heteronuclear Correlation (HETCOR) spectroscopy.

\section{EXPERIMENTAL}

2.1 Sample Synthesis. Six silica aerogel samples have been prepared according to classical synthesis procedures from the literature (Table 1). A typical two-step TEOS based silica aerogel was hydrophobized with HMDZ in heptane (1) ${ }^{14}$. A PEDS based aerogel was hydrophobized with HMDSO in ethanol (2) ${ }^{33}$. Two waterglass based aerogels were hydrophobized in heptane with TMCS, either without (3) or with (4) a previous solvent exchange from water to ethanol ${ }^{18}$. Inherently superhydrophobic MTMS (5) and MTMS+DMDMS (6) open-porous foams did not require an additional hydrophobization step ${ }^{12}$. All samples were prepared by ambient pressure drying according to the conditions listed in Table 1 and the detailed description in the Supplementary Information. 


\begin{tabular}{|c|c|c|c|c|c|c|}
\hline \multirow[b]{2}{*}{ Sample number } & \multicolumn{4}{|c|}{ Silica aerogels } & \multicolumn{2}{|c|}{ Open-porous silica foams } \\
\hline & 1 & 2 & 3 & 4 & 5 & 6 \\
\hline Sample name & TEOS/HMDZ & PEDS/HMDSO & WG/TMCS & WG/SE/TMCS & MTMS & MTMS+DMDMS \\
\hline Reference & Rao et al. 2001, 2005 & Pajonk et al. 1995 & Wang et al. 2009 & Wang et al. 2009 & Bhagat et al. 2007 & Hayase et al. 2011 \\
\hline Precursors & TEOS in ethanol & PEDS in EtOH & Waterglass & Waterglass & MTMS & MTMS+DMDMS \\
\hline Washing & EtOH $(2 x), n$-heptane $(4 x)$ & - & $-\quad$ & EtOH $(3 x), n$-heptane $(4 x)$ & - & $\mathrm{H}_{2} \mathrm{O}(2 \mathrm{x}), \mathrm{EtOH}(2 \mathrm{x})$ \\
\hline Hydrophobe & HMDZ in $\mathrm{n}$-heptane & $\mathrm{HMDSO}$ in $\mathrm{EtOH}$ & TMCS in EtOH/n-heptane & TMCS in n-heptane & - & - \\
\hline Washing & $\mathrm{n}$-heptane $(4 \mathrm{x})$ & - & - & - & - & - \\
\hline Density $\rho\left(\mathrm{g} / \mathrm{cm}^{3}\right)$ & 0.203 & 0.113 & 0.135 & 0.136 & 0.171 & 0.105 \\
\hline \multicolumn{7}{|l|}{ Particle diameter $(\mathrm{nm})$} \\
\hline - TEM & 6.1 & 6.7 & 5.0 & 5.6 & - & - \\
\hline - NMR (without TMS correction) & 4.6 & 4.5 & 3.7 & 3.0 & - & - \\
\hline - NMR (with TMS correction) & 5.3 & 5.2 & 4.4 & 3.7 & - & - \\
\hline \multicolumn{7}{|l|}{ Surface area $\left(\mathrm{m}^{2} / \mathrm{g}\right)$} \\
\hline$-\mathrm{S}_{\mathrm{BET}}$ & 602 & 733 & 637 & 773 & 385 & b \\
\hline$-\mathrm{S}_{\mathrm{NMR}}($ see text) & 593 & 606 & 737 & 909 & - & - \\
\hline \multicolumn{7}{|l|}{ Pore volume $\left(\mathrm{cm}^{3} / \mathrm{g}\right)$} \\
\hline - from density $\left(V=1 / p-1 / \rho_{0}\right)^{a}$ & 4.5 & 8.4 & 7.0 & 6.9 & 5.3 & 9.0 \\
\hline - BJH adsorption (1.7-300 nm) & 3.7 & 3.8 & 4.0 & 3.6 & 0.2 & $b$ \\
\hline \multicolumn{7}{|l|}{ Average pore diameter $(\mathrm{nm})$} \\
\hline - from $4 \cdot V / S_{\text {BET }}$ & 30 & 46 & 44 & 36 & 55 & b \\
\hline
\end{tabular}

Estimated uncertainties: density: $5 \%$ relative; particle diameter TEM: $1-1.5 \mathrm{~nm}$ (1 S.D.); $\mathrm{S}_{\text {BET: }}$ around $50 \mathrm{~m}^{2} / \mathrm{g}$; Pore volume from density: $10 \%$ relative

${ }^{a} \rho_{0}=$ skeleton density, approximated by the density $\mathrm{SiO}_{2}$ glass $\left(2.20 \mathrm{~g} / \mathrm{cm}^{3}\right)$ for samples $1-4$, and by $1.80 \mathrm{~g} / \mathrm{cm}^{3}$ for samples $5-6$.

${ }^{b}$ Sample had insufficient nitrogen sorption for meaningful BET analysis due to very low surface area and large pore sizes.

2.2 Basic Characterization. The envelope density was determined from the mass and the volume measured by powder pycnometry (Micromeritics, GeoPyc 1360) for samples 1-4, and by its dimensions for samples 5-6 as these latter materials are too compressible to be measured by the powder displacement method. The specific surface area and volume fraction of mesopores were determined from the nitrogen sorption data (Micromeritics, TriFlex) using Brunauer-Emmet-Teller (BET) analysis ${ }^{34}$ and Barrett-Joyner-Halenda $(\mathrm{BJH})$ analysis ${ }^{35}$. The average pore diameter was calculated from the pore volume and surface area rather than the $\mathrm{BJH}$ analysis as the latter is known to be affected by the sample deformation during nitrogen sorption experiments ${ }^{36}$. The $\mathrm{C}$ and $\mathrm{H}$ content were determined by standard elemental analysis (combustion and subsequent gas-phase FTIR analysis) at the Laboratory for Organic Chemistry of ETH Zurich.

2.3 Electron Microscopy. Transmission electron microscopy (TEM) images were recorded with a JEOL2200FS microscope operated at an accelerating voltage of $200 \mathrm{kV}$. The samples were crushed and dispersed in methanol and the resulting dispersion was then dropped onto thin carbon grids and allowed to evaporate at room temperature. Care has been taken to avoid beam-induced modification 
of the aerogel morphology by using short exposure times with a low electron dose. Scanning Electron Microscopy (SEM) images of all samples were acquired with a FEI Nova NanoSEM 230 instrument (FEI, Hillsboro, Oregon, USA) at an accelerating voltage of $10 \mathrm{kV}$ and a working distance of $5 \mathrm{~mm}$. The silica aerogels were fixed on the sample holder using a carbon pad and subsequently coated with 10-15 nm of platinum for SEM analysis.

2.4 Solid-State NMR spectroscopy. The NMR procedures closely follow those established in our previous NMR study on silica aerogel ${ }^{33}$ and all spectra were processed with matNMR ${ }^{37}$. Quantitative Magic Angle Spinning (MAS) solid-state ${ }^{1} \mathrm{H},{ }^{13} \mathrm{C}$ and ${ }^{29} \mathrm{Si}$ NMR spectra were recorded with wide-bore 9.4 T magnets, corresponding to Larmor frequencies of $400.2,100.6$ and $79.5 \mathrm{MHz}$ for ${ }^{1} \mathrm{H},{ }^{13} \mathrm{C}$ and ${ }^{29} \mathrm{Si}$, respectively. We employed spectral widths and acquisition times of $249.9 \mathrm{ppm}$ and $328 \mathrm{~ms}, 219.2 \mathrm{ppm}$ and $93 \mathrm{~ms}$, and $349.3 \mathrm{ppm}$ and $74 \mathrm{~ms}$, for ${ }^{1} \mathrm{H},{ }^{13} \mathrm{C}$ and ${ }^{29} \mathrm{Si}$, respectively. The ${ }^{1} \mathrm{H}$ NMR spectra were recorded on an Avance III system applying a $24 \mathrm{kHz}$ MAS rate in $2.5 \mathrm{~mm}$ zirconia rotors to minimize line-widths. The ${ }^{13} \mathrm{C}$ and ${ }^{29} \mathrm{Si}$ NMR spectra were recorded on a Bruker Avance III HD system with a MAS rate of $4 \mathrm{kHz}$ in $7 \mathrm{~mm}$ zirconia rotors to maximize signal to noise. All spectra were collected with a recycle delay of at least $5 \cdot T 1$, as determined by saturation recovery experiments, to ensure their quantitative nature. Fully relaxed spectra were also collected for adamantane $\left({ }^{1} \mathrm{H}\right.$ and $\left.{ }^{13} \mathrm{C}\right)$, octakis(trimethylsiloxy)silsesquioxane (Q8M8) $\left({ }^{1} \mathrm{H}_{1}{ }^{13} \mathrm{C},{ }^{29} \mathrm{Si}\right)$ and tetrakis(trimethylsilyl)silane $\left({ }^{1} \mathrm{H},{ }^{13} \mathrm{C}\right.$, ${ }^{29}$ Si) to calibrate the absolute NMR signal intensities. All samples and standards were measured on completely filled rotors to ensure that potential inhomogeneity in sensitivity due to gradients in the radio-frequency (RF) field strength cancel out during the intensity calibration and with sufficiently strong pulses to ensure uniform excitation: 83,45 and $21 \mathrm{kHz}$ for ${ }^{1} \mathrm{H},{ }^{13} \mathrm{C}$ and ${ }^{29} \mathrm{Si}$, respectively ${ }^{33}$. No background contributions were detected for ${ }^{13} \mathrm{C}$ and ${ }^{29} \mathrm{Si}$. The ${ }^{1} \mathrm{H}$ background signal from an empty rotor was subtracted.

The high ${ }^{1} \mathrm{H}$ NMR sensitivity results in acquisition times of just a few minutes and establishes ${ }^{1} \mathrm{H}$ NMR as a tool to screen large numbers of samples if the spectra are sufficiently resolved. Despite the 
inherently low ${ }^{13} \mathrm{C}$ and ${ }^{29} \mathrm{Si}$ NMR sensitivity and the further loss of sensitivity due to the low sample density, quantitative ${ }^{13} \mathrm{C}$ and ${ }^{29} \mathrm{Si}$ NMR spectra with acceptable signal to noise ratios can be collected within around 2 and 10 hours, respectively. These relatively short acquisition times are mainly due to the relatively short $T 1$ relaxation times of $2-25 \mathrm{~s}$ for ${ }^{13} \mathrm{C}$ and $30-180 \mathrm{~s}$ for ${ }^{29} \mathrm{Si}$, enabling relatively high repetition rates, even for recycle delays $>5 \cdot T 1$. For comparison, ${ }^{29} \mathrm{Si} T 1$ relaxation times in bulk silica glass can be as long as 7 hours, i.e. two to three orders of magnitude longer ${ }^{38}$. The high surface area of nanoscale materials and the resulting high concentrations of surface groups further increase sensitivity.

In addition to the quantitative NMR spectra, two-dimensional ${ }^{1} \mathrm{H}_{-}{ }^{29} \mathrm{Si} \mathrm{HETCOR}$ spectra have been acquired to investigate the connectivity between the different sites ${ }^{39}$. The HETCOR spectra were collected on a Bruker Avance III HD spectrometer with a wide-bore 16.4 T magnet, corresponding to Larmor frequencies of 700 and $139.1 \mathrm{MHz}$ for ${ }^{1} \mathrm{H}$ and ${ }^{29} \mathrm{Si}$, respectively. We selected $4 \mathrm{~mm}$ zirconia rotors with a spinning rate of $10 \mathrm{kHz}$ as a compromise between sensitivity and spectral resolution in the ${ }^{1} \mathrm{H}$ dimension. Homonuclear dipolar decoupling using continuous phase modulation (DUMBO) was applied to improve the spectral resolution in the ${ }^{1} \mathrm{H}$ dimension ${ }^{40}$.

\section{RESULTS AND DISCUSSION}

3.1 Basic characterization. The density, BET surface area, porosity, pore size and other physical properties are summarized in Table 1. The nitrogen sorption curves are plotted in Fig. S2. The silica aerogels senso stricto (based on silica precursors with 4 oxygen neighbors per Si atom, samples 1-4) are brittle materials with densities between 0.113 and $0.205 \mathrm{~g} / \mathrm{cm}^{3}$ and surface areas between 602 and $773 \mathrm{~m}^{2} / \mathrm{g}$. The MTMS-based open-porous foam (5) has a density of $0.171 \mathrm{~g} / \mathrm{cm}^{3}$ and a surface area of $385 \mathrm{~m}^{2} / \mathrm{g}$ and is somewhat flexible. The MTMS+DMDMS based open-porous foam (6) has a density of $0.105 \mathrm{~g} / \mathrm{cm}^{3}$, a surface area too small to be determined by BET and is super-flexible. Aerogels 1-4 
display the typical blue hue from the Rayleigh scattering originating from the silica aerogel mesopores (Fig. S1). In contrast, the milky appearance of open-porous foams 5 and 6 is indicative of the presence of larger macropores, as confirmed by SEM microscopy (see below) and the inability of nitrogen sorption to adequately probe the pore sizes of both samples (Table 1, Fig. S2).

3.2 Electron microscopy. The TEM images of the silylated silica aerogel samples demonstrate the typical pearl-necklace morphology with silica particles linked by inter-particle necks (Fig. 1). The particle sizes are somewhat larger for the alkoxide (1-2) than for the waterglass (3-4) based aerogels (Table 1). The SEM images for the silylated samples (1-4) display the typical silica aerogel morphologies with mesopores enclosed by secondary particle aggregates of ca. 20-50 nm in diameter (Fig. 2). Secondary particle in this size range were observed previously by SEM and SAXS for silica and silica-polymer hybrid aerogels ${ }^{41}$. The MTMS and DMDMS based open-porous foams (samples 5-6) display radically different morphologies with much larger pore sizes, particularly for sample 6 .
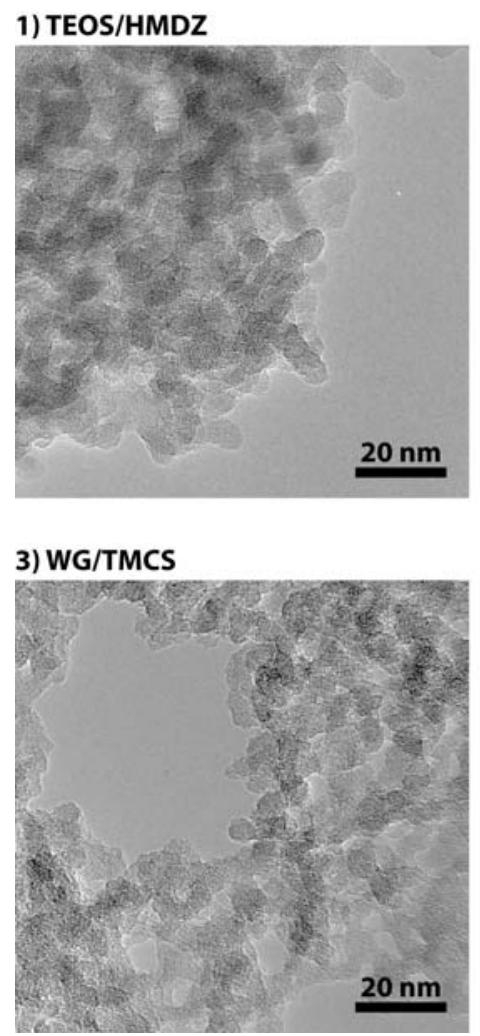

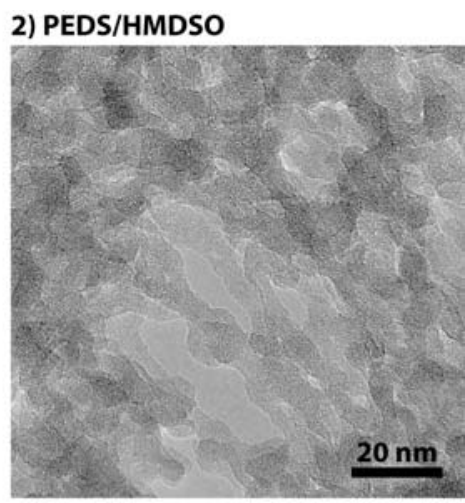

\section{4) WG/SE/TMCS}

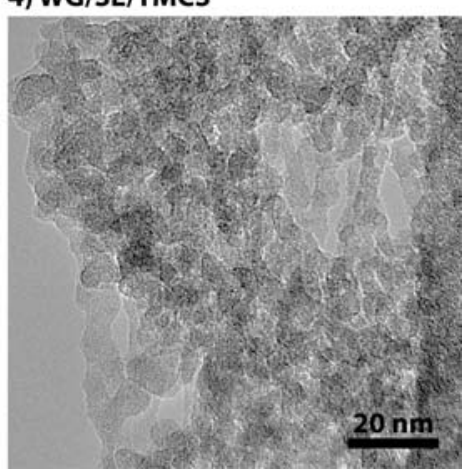

Figure 1. TEM images of four archetypal silica aerogels. 

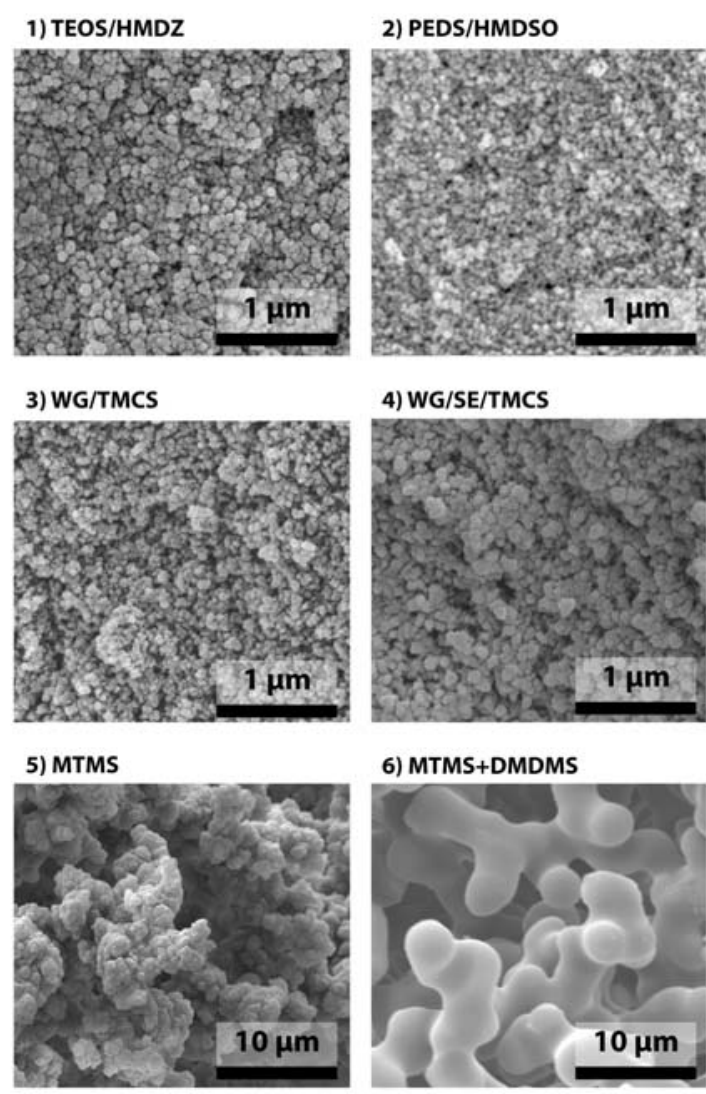

6) MTMS+DMDMS

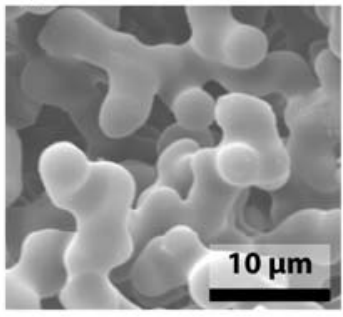

Figure 2. SEM images of six archetypal silica aerogels and open-porous foams. Samples 1-4 are true aerogels with mesopores in the 10-40 nm range. The MTMS, and particularly the MTMS+DMDMS samples (5-6), are open-porous foams with much larger pores.

3.3 Quantitative NMR spectra. The quantitative ${ }^{29}$ Si NMR spectra display all the peaks expected for hydrophobic silica aerogel materials (Fig. 3c) ${ }^{25,31-33}$. Aerogels 1-4 consist of silica with 76 to $90 \% Q^{4}$ and 10 to $24 \% Q^{3}$, where $Q^{n}$ denotes a tetrahedral Si with $n$ bridging oxygen $(B O)$ and $(n-1)$ nonbridging oxygen (NBO) (Table S1, Fig. 3c, Fig. S3). These samples also display a clear ${ }^{29}$ Si NMR peak for TMS. The MTMS derived open-porous foam (5) consists of $\mathrm{T}^{3}$ and $\mathrm{T}^{2}$ sites, where $\mathrm{T}^{\mathrm{n}}$ stands for a tetrahedral Si with $1 \mathrm{C}, \mathrm{n}$ BO and (3-n) NBO neighbors in a molar 86:14 $\mathrm{T}^{3}: \mathrm{T}^{2}$ ratio (Table S2, Fig. $\left.3 \mathrm{c}\right)^{25}$. The MTMS+DMDMS derived open-porous foam (6) contains $T^{3}: T^{2}: D^{2}: D^{1}$ in a 52:6:38:4 molar proportion, where $D^{n}$ is a Si tetrahedron with 2 neighbouring $C$ atoms as well as $n$ BO and (2-n) NBO (Table S2, Fig. 3c). The quantitative ${ }^{1} \mathrm{H}$ and ${ }^{13} \mathrm{C}$ spectra (Fig. 3a,b) give further insight into the silica chemistry. They confirm the presence of TMS groups for the silylated samples (1-4) in addition to a 
minor fraction of ethoxy groups $\left(\equiv \mathrm{Si}\left(\mathrm{Q}^{3}\right)-\mathrm{O}-\mathrm{CH}_{2}-\mathrm{CH}_{3}\right.$, see HETCOR data below) and in the case of sample 3, a small fraction of $\equiv \mathrm{Si}-\mathrm{OH}$ (see HETCOR data below). Samples 3 and 4 also contain minor peaks related to impurities from the exchange resin. The quantitative ${ }^{1} \mathrm{H}$ and ${ }^{13} \mathrm{C}$ spectra of the MTMS derived sample (5) confirm the presence of methyl groups linked to the $\mathrm{T}$ sites, $\equiv \mathrm{Si}(\mathrm{T})-\mathrm{CH}_{3}$ (see HETCOR data below) and a minor peak associated with methoxy groups $\left(\equiv \mathrm{Si}\left(\mathrm{T}^{2}\right)-\mathrm{O}-\mathrm{CH}_{3}\right)$. The quantitative ${ }^{13} \mathrm{C}$ spectrum of the MTMS+DMDMS derived sample (6) confirms the presence of both T and $\mathrm{D}$ groups. Unlike the ${ }^{13} \mathrm{C}$ spectrum, the ${ }^{1} \mathrm{H}$ spectrum is unable to resolve both types of methyl groups, but the ${ }^{1} \mathrm{H}$ NMR is sensitive enough to detect a very minor peak associated with methoxy groups. Note that the detection of minor amounts of silanol $(\equiv \mathrm{Si}-\mathrm{OH})$ is difficult with NMR because this species contains only a single $\mathrm{H}$ atom (compared to 3,5 and 9 for methoxy, ethoxy and TMS groups, respectively) and because silanol groups are characterized by broad ${ }^{1} \mathrm{H}$ NMR lines that shift depending on the strength of the hydrogen bonding ${ }^{42}$. The silanol content can be estimated indirectly from the difference in $\mathrm{Q}^{3}$ and ethoxy content, assuming that each $\mathrm{Q}^{3}$ species is linked to either an ethoxy or a hydroxyl group (Table 2). 

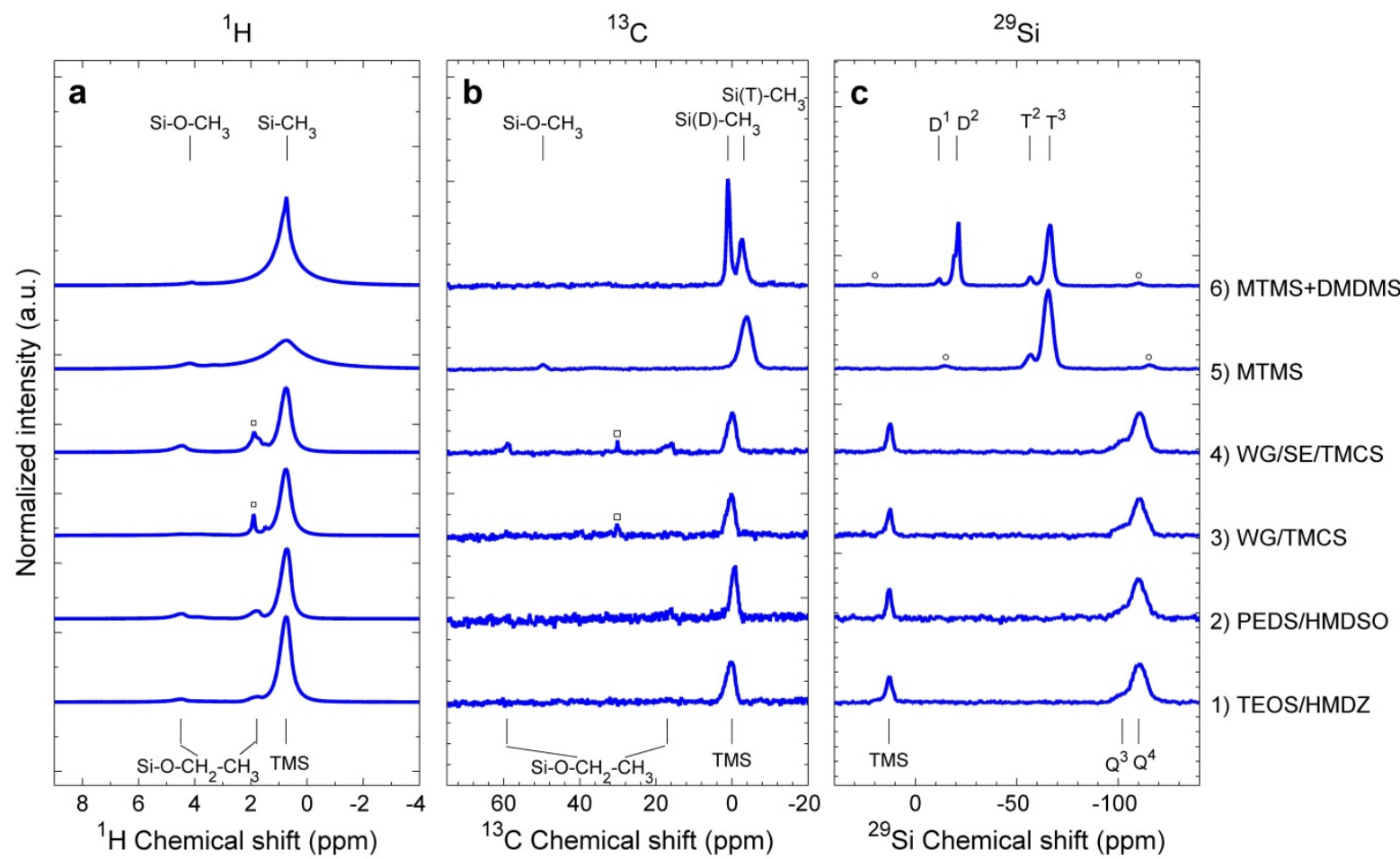

Fig. 3. Quantitative ${ }^{1} \mathrm{H}(a),{ }^{13} \mathrm{C}$ (b) and ${ }^{29} \mathrm{Si}$ (c) NMR spectra of six archetypal silica materials. The round markers denote spinning sidebands; the squares denote peaks due to an unidentified impurity in the waterglass based samples, presumably from the exchange resin.

3.4 Calibration and validation. Without calibration, only ratios of different chemical species can be quantified from fully relaxed NMR spectra (Fig. 3). In a recent study, we demonstrated that it is possible to calibrate the absolute spectral intensities by external calibration with standard samples ${ }^{33}$. Such an external calibration allows one to determine the absolute content of specific sites in a sample and to correlate the NMR data from different nuclei. The slopes of the ${ }^{1} \mathrm{H}_{1}{ }^{13} \mathrm{C}$ and ${ }^{29} \mathrm{Si}$ calibration curves (Fig. 4a-c, Table S5) enable the estimation of the absolute amount of each nucleus and species in the sample. The $\mathrm{H}, \mathrm{C}$ and $\mathrm{Si}$ content can be derived directly from the NMR spectra and the $\mathrm{O}$ content can be calculated from the ${ }^{29} \mathrm{Si} N M R$ data according to $\left[\mathrm{O}_{\text {total }}\right]=2\left[\mathrm{Q}^{4}\right]+2.5\left[\mathrm{Q}^{3}\right]+0.5[\mathrm{TMS}]$ (in moles). Thus, the total weight of sample in the rotor can be estimated from the NMR data alone and this provides a first validation of the quantification procedure (Table S3, Fig. 4d). A second validation is provided by comparing the $\mathrm{H}$ and $\mathrm{C}$ content derived by NMR with those derived by elemental analysis 
(Fig. 4e, Table S4). A final validation is provided by the consistency between the different measurements: the ${ }^{1} \mathrm{H},{ }^{13} \mathrm{C}$ and ${ }^{29} \mathrm{Si}$ data give consistent estimates for the content of the various molecular groups (T and D sites, TMS and ethoxy groups) (Table 2, Fig. 4f).
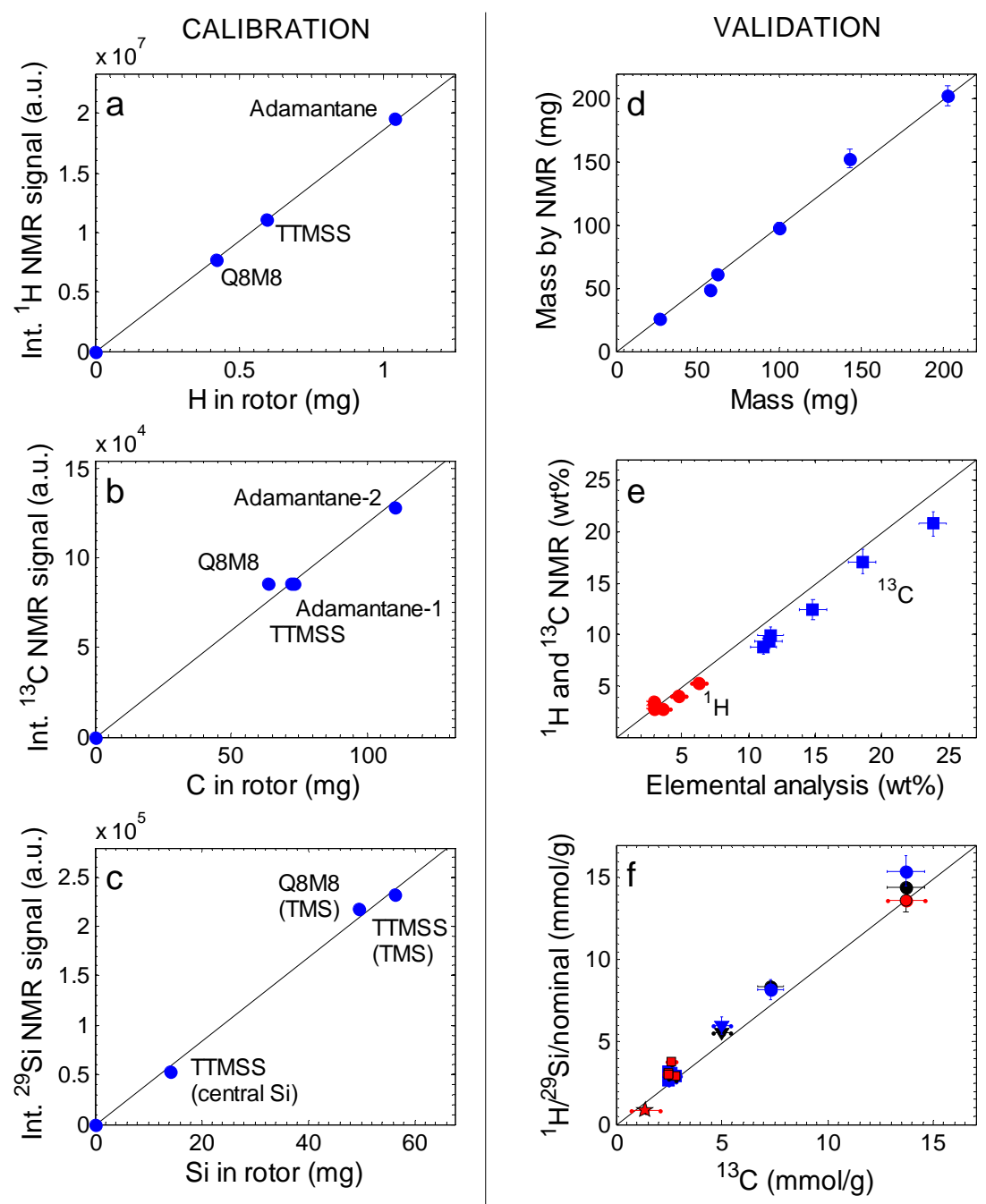

Fig. 4. Calibration (a-c) and validation (d-f) of the ${ }^{1} \mathrm{H}^{13} \mathrm{C}$ and ${ }^{29}$ Si MAS NMR data. a) ${ }^{1} \mathrm{H}$ calibration, b) ${ }^{13} \mathrm{C}$ calibration, c) ${ }^{29} \mathrm{Si}$ calibration, d) validation by total mass in rotor, e) validation by elemental analysis, f) internal consistency; red: ${ }^{1} \mathrm{H}$, blue: ${ }^{29}$ Si, black: nominal composition, squares: TMS, triangle: $D$ sites, circles: $T$ sites, star: ethoxy groups.

3.5 The composition of silica aerogels and open-porous foams. The silylated aerogels (1-4) display remarkably similar NMR spectra (Fig. 3) and bulk and surface chemistries (Table 2) despite their very different precursors (alkoxide, waterglass), hydrophobization agents (HMDZ, HMDSO and TMCS) and 
gelation and hydrophobization solvents (water, ethanol, $\mathrm{n}$-heptane): the TMS content is nearly constant between $22-27 \mathrm{wt} \%$, the amount of ethoxy groups ranges from 0 to $4 \mathrm{wt} \%$ and also the silica speciation displays a narrow range: $0.10 \leq Q^{3} /\left(Q^{3}+Q^{4}\right) \leq 0.24$. These similarities in chemistry result in aerogels with near-identical morphology (Figs. 1,2) and properties for samples prepared from different precursors ${ }^{43}$. The surface chemistry of silylated silica aerogels and its dependence on the processing conditions will be discussed in more detail in Section 3.8 .

The MTMS and MTMS/DMDMS based silica open-porous foams (5-6) display completely different chemistries compared to the silylated aerogel samples (1-4). The $\mathrm{Si}$ is present as $T^{n}$ and $D^{n}$ species, whose concentrations directly correspond to the MTMS/DMDMS ratio of the precursors (Table 2). Note that, contrary to sample 4, no ethoxy groups can be detected in the spectra of the MTMS+DMDMS open-porous foam (6), indicating that the alcoholysis is not efficient for this sample even though it was washed in ethanol multiple times. The reduction in BO/Si from 3.76-3.89 for aerogels (1-4) to 2.86 for the MTMS (5) and 2.48 for the MTMS+DMDMS (6) derived open-porous foams (Table S1, Table S2) results in a drastic change of the microstructural and physical properties from predominantly mesoporous to predominantly macroporous (Table 1 ) and from brittle to superflexible, particularly in combination with ambient drying processes ${ }^{12,22,23}$. 


\begin{tabular}{|c|c|c|c|c|c|c|c|c|}
\hline & & & TEOS/HMDZ & PEDS/HMDSO & WG/TMCS & WG/SE/TMCS & MTMS & MTMS+DMDMS \\
\hline & & & 1 & 2 & 3 & 4 & 5 & 6 \\
\hline $\mathrm{Q}^{4}$ & $\mathrm{SiO}_{2}$ & ${ }^{29} \mathrm{Si}$ & $10.8 \pm 0.7$ & $10.5 \pm 0.7$ & $8.4 \pm 0.6$ & $8.6 \pm 0.6$ & & \\
\hline$Q^{3}$ & $\equiv \mathrm{Si}-\mathrm{O}_{\mathrm{NBO}}$ & ${ }^{29} \mathrm{Si}$ & $1.3 \pm 0.1$ & $1.5 \pm 0.1$ & $1.7 \pm 0.1$ & $2.7 \pm 0.2$ & & \\
\hline \multirow[t]{3}{*}{ TMS } & $\equiv \mathrm{Si}-\mathrm{O}-\mathrm{Si}\left(\mathrm{CH}_{3}\right)^{3}$ & ${ }^{1} \mathrm{H}$ & $3.8 \pm 0.2$ & $2.9 \pm 0.2$ & $3.1 \pm 0.2$ & $3.0 \pm 0.2$ & & \\
\hline & & ${ }^{13} \mathrm{C}$ & $2.6 \pm 0.2$ & $2.8 \pm 0.2$ & $2.5 \pm 0.2$ & $2.5 \pm 0.2$ & & \\
\hline & & ${ }^{29} \mathrm{Si}$ & $3.1 \pm 0.3$ & $2.9 \pm 0.3$ & $2.7 \pm 0.3$ & $3.2 \pm 0.3$ & & \\
\hline \multirow[t]{4}{*}{ Ethoxy } & $\equiv \mathrm{Si}-\mathrm{O}-\mathrm{CH}_{2}-\mathrm{CH}_{3}$ & ${ }^{1} \mathrm{H}\left(\mathrm{CH}_{3}\right)$ & $0.3 \pm 0.1$ & $0.6 \pm 0.1$ & $<\mathrm{LOD}$ & $0.9 \pm 0.1$ & & \\
\hline & & ${ }^{1} \mathrm{H}\left(\mathrm{CH}_{2}\right)$ & $0.3 \pm 0.1$ & $0.5 \pm 0.1$ & $<\mathrm{LOD}$ & $0.8 \pm 0.1$ & & \\
\hline & & ${ }^{13} \mathrm{C}\left(\mathrm{CH}_{3}\right)$ & $<\mathrm{LOD}$ & $<\mathrm{LOD}$ & $<\mathrm{LOD}$ & $1.6 \pm 0.8$ & & \\
\hline & & ${ }^{13} \mathrm{C}\left(\mathrm{CH}_{2}\right)$ & $<\mathrm{LOD}$ & $<\mathrm{LOD}$ & $<$ LOD & $1.2 \pm 0.6$ & & \\
\hline Silanol ${ }^{b}$ & $\equiv \mathrm{Si}-\mathrm{OH}$ & $Q^{3}$-Ethoxy & $1.0 \pm 0.1$ & $1.0 \pm 0.1$ & $1.7 \pm 0.1$ & $1.8 \pm 0.2$ & & \\
\hline \multirow[t]{4}{*}{$T$ sites } & $\equiv \mathrm{Si}(\mathrm{T})-\mathrm{CH}_{3}$ & ${ }^{1} \mathrm{H}$ & & & & & $13.6 \pm 0.7$ & not resolved \\
\hline & & ${ }^{13} \mathrm{C}$ & & & & & $13.7 \pm 0.9$ & $7.3 \pm 0.6$ \\
\hline & & ${ }^{29} \mathrm{Si}$ & & & & & $15.4 \pm 0.9$ & $8.2 \pm 0.6$ \\
\hline & & nominal $^{a}$ & & & & & $14.4 \pm 0.3$ & $8.4 \pm 0.2$ \\
\hline \multirow[t]{4}{*}{ D sites } & $\equiv \mathrm{Si}(\mathrm{D})-\mathrm{CH}_{3}$ & ${ }^{1} \mathrm{H}$ & & & & & & not resolved \\
\hline & & ${ }^{13} \mathrm{C}$ & & & & & & $5.0 \pm 0.4$ \\
\hline & & ${ }^{29} \mathrm{Si}$ & & & & & & $6.0 \pm 0.5$ \\
\hline & & nominal $^{\mathrm{a}}$ & & & & & & $5.6 \pm 0.2$ \\
\hline
\end{tabular}

\footnotetext{
${ }^{a}$ Calculated from starting materials and $\mathrm{T}^{n}$ and $\mathrm{D}^{\mathrm{n}}$ speciation derived from the ${ }^{29} \mathrm{Si}$ NMR spectra.

${ }^{b}$ Determined indirectly assuming each $Q^{3}$ has either an ethoxy or a silanol neighbor.

LOD: Limit of detection
}

3.6 Site connectivity. The ${ }^{1} \mathrm{H}_{-}{ }^{29} \mathrm{Si}$ HETCOR spectra (Fig. 5) inform on the connectivity between the various silica sites and functional groups. These spectra rely on the dipolar coupling and give information about the spatial proximity between the ${ }^{1} \mathrm{H}$ and ${ }^{29} \mathrm{Si}$, but not a priori about chemical bonding. For all silylated samples (Fig. 5a-d), the TMS protons strongly correlate not only to TMS Si, but also to $Q^{4}$, indicating the successful chemical grafting of TMS groups during hydrophobization where a $\mathrm{Q}^{3}-\mathrm{OH}$ is converted into a $\mathrm{Q}^{4}$-TMS connection. Additional weak peaks are interpreted as $\mathrm{Q}^{3}$ $\mathrm{OCH}_{2} \mathrm{CH}_{3}$ (Fig. 5b,d) and $\mathrm{Q}^{3}-\mathrm{OH}$ (Fig. 5c). The ethoxy $\mathrm{CH}_{3}$ to TMS Si correlation (Fig. 5d) indicates that TMS and ethoxy groups are interspersed to some extent on the silica surface, i.e. TMS and ethoxy form a non-phase-separated monolayer on the silica surface. The spectra for the MTMS and MTMS+DMDMS based samples (Fig. 5e,f) show strong correlations of the methyl protons to all silica sites $\left(T^{3}, T^{2}, D^{2}, D^{1}\right)$ as expected since all these Si sites are connected to at least one methyl group. Note that the DUMBO sequence suppresses most of the dipolar broadening, with narrower peaks in the ${ }^{1} \mathrm{H}$ projection of the HETCOR spectra than in the quantitative ${ }^{1} \mathrm{H}$ spectra, even though the latter 
were collected at a higher MAS rate $(24 \mathrm{kHz}$ versus $10 \mathrm{kHz})$. Nevertheless, the suppression of the dipolar broadening by DUMBO is incomplete, resulting in residual vertical tails to the peaks. The spectrum of the MTMS based sample displays two minor cross peaks between the methoxy protons and the $\mathrm{T}^{2}$ and $\mathrm{T}^{3}$ sites. This methoxy can either be residual from the MTMS precursor or originate from the methanol solvent through alcoholysis reactions such as $=\mathrm{Si}\left(\mathrm{CH}_{3}\right)(\mathrm{OH})+\mathrm{CH}_{3} \mathrm{OH} \leftrightarrow$ $=\mathrm{Si}\left(\mathrm{CH}_{3}\right)\left(\mathrm{OCH}_{3}\right)+\mathrm{H}_{2} \mathrm{O}$. The intensity of the correlation to $\mathrm{T}^{2}$ is enhanced compared to the $\mathrm{T}^{2} / \mathrm{T}^{3}$ ratio: a T site linked to a methoxy group inevitably has a NBO and is a $\mathrm{T}^{2}$ site, whereas $\mathrm{T}^{3}$ sites by definition cannot be connected to a methoxy group. 


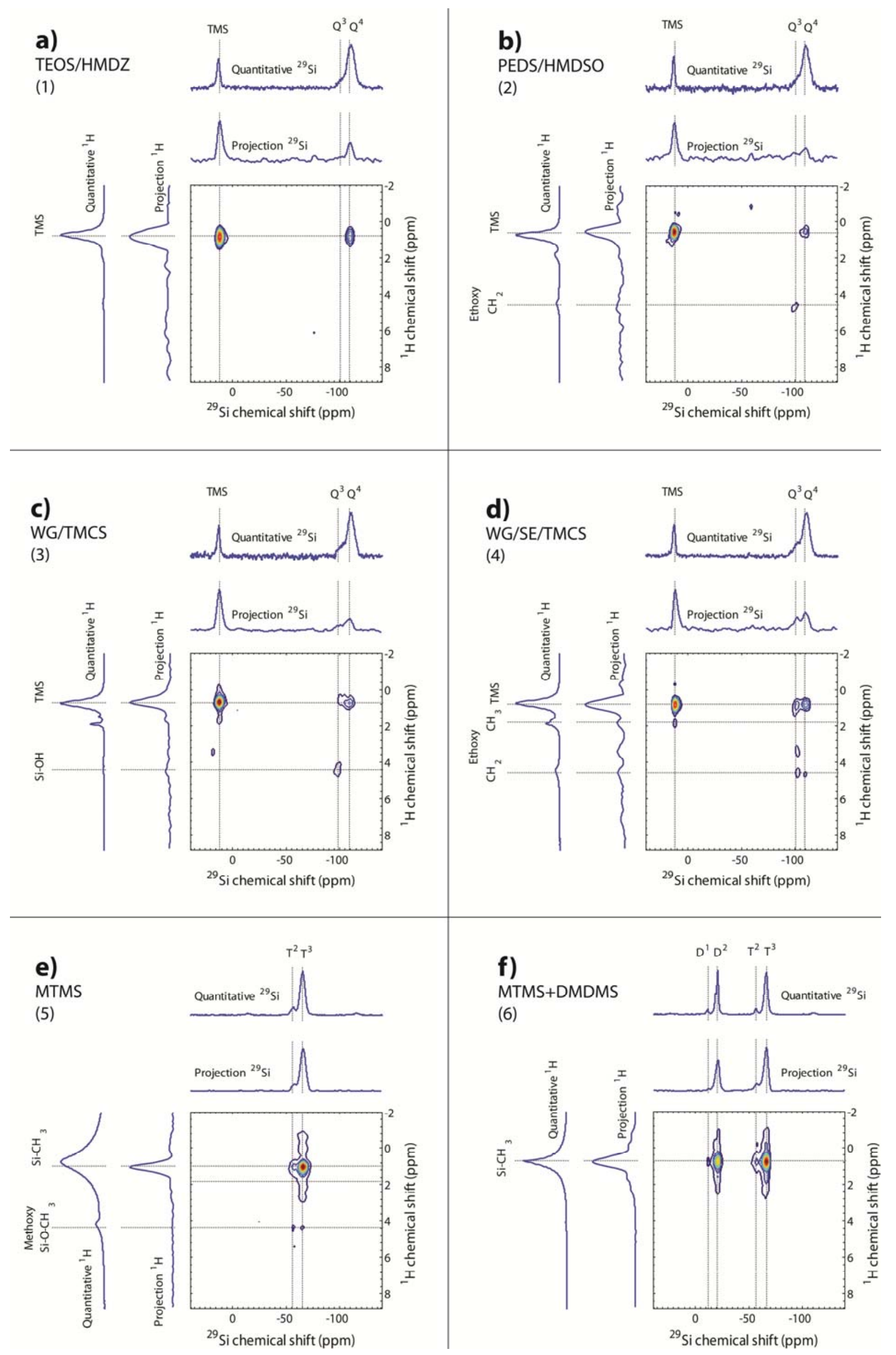


Fig. $5 .{ }^{1} \mathrm{H}_{-}^{29}$ Si heteronuclear solid state NMR spectra of classical silica aerogels and open-porous foams together with their ${ }^{1} \mathrm{H}$ and ${ }^{29} \mathrm{Si}$ projections and quantitative ${ }^{1} \mathrm{H}$ and ${ }^{29} \mathrm{Si}$ spectra. Lowest intensity contours at a) $20 \%$, b) $25 \%$, c) $12 \%$, d) $20 \%$, e) $2.5 \%$ and f) $5 \%$ of the maximum intensity.

3.7 Particle size and surface area. The silica speciation data can be used to estimate the primary particle size of the silylated silica aerogels by comparing the NMR derived internal versus surface Si ratio to a theoretical prediction of that ratio as a function of particle size (Fig. 6). This estimate depends on a number of approximations. 1) The silica particle interior consists entirely of fully cross-linked silica, i.e. $Q^{4}$ groups only, and the particle surface layer consist entirely of $Q^{3}$ species (with either a hydroxyl or ethoxy group linked to the NBO) or $\mathrm{Q}^{4}$ linked to a TMS group. The latter species represents a $\mathrm{Q}^{3}$ species that was converted into a $\mathrm{Q}^{4}$ during hydrophobization. Under this assumption, the internal/surface Si ratio equals $\left.\left(\left[\mathrm{Q}^{4}\right]-[\mathrm{TMS}]\right) /\left(\left[\mathrm{Q}^{3}\right]+[\mathrm{TMS}]\right) .2\right)$ The thickness of the surface layer is assumed to be $0.357 \mathrm{~nm}$, the edge length of a cube with a volume that contains a single Si atom, for a density approximated by that of bulk silica glass, $2.20 \mathrm{~g} / \mathrm{cm}^{3}$, i.e. $0.0454 \mathrm{~nm}^{3}$. 3) The silica particles are assumed to be spherical and the loss of surface area at inter-particle necks is not taken into account. Under these approximations, the estimated particle sizes are around 3-3.5 $\mathrm{nm}$ for the waterglass (3-4) and $4.5 \mathrm{~nm}$ for the alkoxide based aerogels (1-2) (Fig. 6, Table 1). Note that these predicted diameters are for the bare particles without their surface coverage and they need to be corrected for the surface layer of TMS and ethoxy groups (+ $\sim 0.7 \mathrm{~nm})$. For comparison, the particle sizes as determined from the TEM images (Fig. 1, Table 1) are around 5.0 to 5.6 for the waterglass based aerogels and around 6.0 to 6.7 for the alkoxide based aerogels. Thus, the indirect NMR approach accurately predicts relative differences in particle size, with smaller particle diameters for the waterglass based aerogels, but systematically underestimates the absolute particle sizes by about 1 to $2 \mathrm{~nm}$ (Table 1, Fig. S4).

The surface area can be estimated from the particle sizes assuming a particle density of $2.20 \mathrm{~g} / \mathrm{cm}^{3}$ and without considering the surface loss at inter-particle necks or the contributions of the TMS, ethoxy and silanol groups to the surface area. This approach results in estimated surface areas on the order of 
$750-900 \mathrm{~m}^{2} / \mathrm{g}$ for the waterglass and $600 \mathrm{~m}^{2} / \mathrm{g}$ for the alkoxide based aerogels (Table 1 ). This indirect NMR approach reproduces the surface area as determined by BET analysis to within $20 \%$ (Table 1, Fig.

S5).
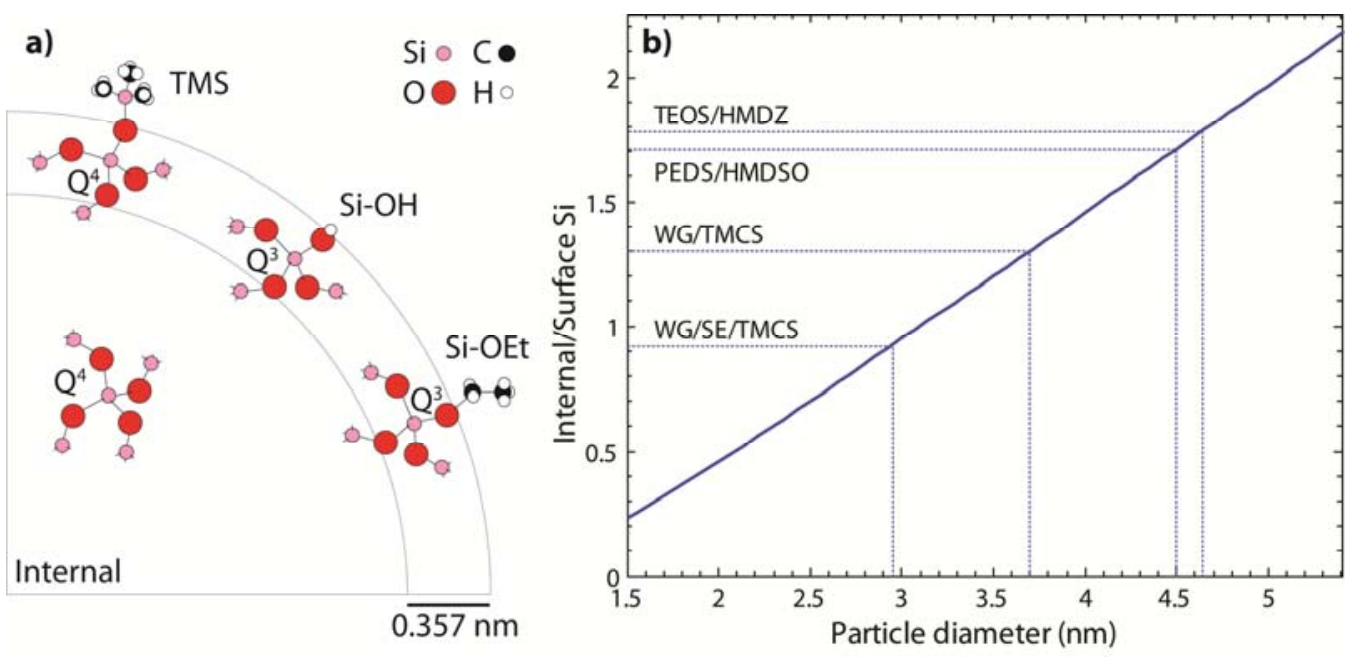

Fig. 6. Particle size derived from NMR data. a) Schematic illustration of a nanoparticle: our calculations assume that the surface layer consists of $Q^{3}$ (with either hydroxyl or ethoxy groups) and $Q^{4}$ attached to TMS groups; the inside of the particle consists exclusively of $Q^{4}$ with four siloxane neighbors. $b$ ) Theoretical internal/surface Si ratio as a function of particle diameter (solid line): combined with our NMR data, this curve results in estimated particle diameters of ca. 3-3.5 nm and ca. $4.5 \mathrm{~nm}$ for the waterglass and alkoxide based aerogels, respectively (see text for model approximations).

3.8 Surface chemistry of silica aerogels. Before silylation, the surfaces of silica (aero)gels consist predominantly of $\mathrm{Q}^{3}$, i.e. Si tetrahedra with three $\equiv \mathrm{Si}-\mathrm{O}-\mathrm{Si} \equiv$ bonds and one $\equiv \mathrm{Si}-\mathrm{OR}$ group. The nature of the functional group attached to the non-bridging oxygen depends on the precursor, solvent system and solvent exchanges during processing, for example $\mathrm{R}$ may be $-\mathrm{H}$ (silanol), $-\mathrm{CH}_{3}$ (methoxy) or $-\mathrm{CH}_{2} \mathrm{CH}_{3}$ (ethoxy). A clear illustration of the processing dependence of the functionality of the $\mathrm{Q}^{3}$ species is that among the silylated aerogel samples (1-4), the amount of ethoxy groups (इSi-O$\mathrm{CH}_{2} \mathrm{CH}_{3}$ ) is highest for a waterglass based aerogel (4), i.e. for a material whose precursors do not 
contain ethoxy groups, but for which the hydrogel was exchanged into ethanol during processing (Fig. 1, Tables 1-2). This observation highlights the efficiency of the alcoholysis reaction $\equiv \mathrm{Si}-\mathrm{OH}+$ $\mathrm{CH}_{3} \mathrm{CH}_{2} \mathrm{OH} \leftrightarrow \equiv \mathrm{Si}-\mathrm{O}-\mathrm{CH}_{2} \mathrm{CH}_{3}+\mathrm{H}_{2} \mathrm{O}$, i.e. the inverse of the classical hydrolysis reaction. In other words, ethoxy groups from the solvent can replace silanol groups on the silica surfaces. The efficiency with which surface groups can exchange with the solvent strongly depends on the chemistry of the exchange liquids and exchange conditions (temperature, time): the waterglass samples have both the lowest (3) and highest (4) ethoxy content of the four investigated aerogels. Note that the notoriously high efficiency of the hydrolysis of alkoxides such as TEOS or TMOS during sol formation is assisted by the continuous removal of one of the main reaction products $(\equiv \mathrm{Si}-\mathrm{OH})$ and the simultaneous regeneration of one of the main reagents $\left(\mathrm{H}_{2} \mathrm{O}\right)$ by condensation reactions $(2 \equiv \mathrm{Si}-\mathrm{OH} \leftrightarrow \equiv \mathrm{Si}-\mathrm{O}-\mathrm{Si} \equiv+$ $\mathrm{H}_{2} \mathrm{O}$ ) that run in parallel to the hydrolysis reaction.

During silylation, at least some but usually the majority of the terminal groups are replaced by trimethylsilyl groups through the formation of $\equiv \mathrm{Si}-\mathrm{O}-\mathrm{Si}\left(\mathrm{CH}_{3}\right)_{3}$ bonds and by converting $\mathrm{Q}^{3}$ into $\mathrm{Q}^{4}$., Thus, the final $\mathrm{Q}^{3} / \mathrm{Q}^{4}$ ratio of a hydrophobic silica aerogel depends on two factors: i) the initial $\mathrm{Q}^{3}$ content which is related to the particle size and surface area and ii) the efficiency of the silylation. An example of this is the somewhat higher proportion of $Q^{3}$ in the waterglass based aerogels (3-4) compared to the alkoxide based materials (1-2), which is primarily due to the smaller particle size (Fig. 1 , see above).

The production of low density, superinsulating silica aerogels by ambient pressure drying typically requires high degrees of silylation: all four investigated samples have ca. $3 \mathrm{mmol} / \mathrm{g}$ of TMS groups (Table 2), corresponding to ca. 4 TMS molecules per $\mathrm{nm}^{2}$ of surface area (BET). For comparison, partially silylated samples with 1.5 to 2 TMS groups per $\mathrm{nm}^{2}$ shrank significantly during drying, with final densities between 0.275 and $0.399 \mathrm{~g} / \mathrm{cm}^{3} 33$. Our results on samples prepared by different synthesis routes (Table 2) demonstrate that sufficiently high degrees of silylation can be achieved by all investigated hydrophobization agents (HMDZ, HMDSO, TMCS). Thus, the final selection of the 
hydrophobization agent will depend on raw materials cost and processing simplicity. The latter is determined by factors such as solvent miscibility and compatibility, corrosion of reaction vessels (e.g. reaction with TMCS produces $\mathrm{HCl}$ ) and reaction kinetics.

\section{CONCLUSIONS}

A wide variety of synthesis routes have been developed for the production of silylated silica aerogels following the feasibility demonstration for ambient pressure drying. The ${ }^{1} \mathrm{H}^{29} \mathrm{Si}$ heteronuclear correlation spectra presented here demonstrate the successful grafting of the TMS groups onto the silica surfaces for all investigated routes. In addition, our quantitative NMR data demonstrate the uniformity in surface chemistry of silylated silica aerogels, regardless of the type of precursor, gelation solvent or hydrophobization agent. This uniformity extends to the morphology, as shown by SEM and TEM, and the macroscopic physical properties. In contrast, silica open-porous foams prepared from MTMS and DMDMS precursors have very different chemistries, morphologies and properties. For the industrial production of silylated, hydrophobic silica aerogel materials, the precursors and processes can be selected primarily on the basis of process simplicity, energy consumption and raw materials cost as all synthesis routes can deliver excellent materials on the laboratory scale.

\section{Acknowledgments}

We thank Lukas Huber for his assistance with the BET measurements and the Laboratory for Organic Chemistry at ETH Zurich for the elemental analysis. D.R. acknowledges financial support from the Swiss National Science Foundation (grant 206021_150638).

\section{Conflict of interest declaration}

The authors declare no competing financial interest. 


\section{Supporting Information Available}

Detailed information on sample synthesis and characterization is available in the supporting information. This material is available free of charge via the Internet at http://pubs.acs.org.

\section{TOC graphical abstract}

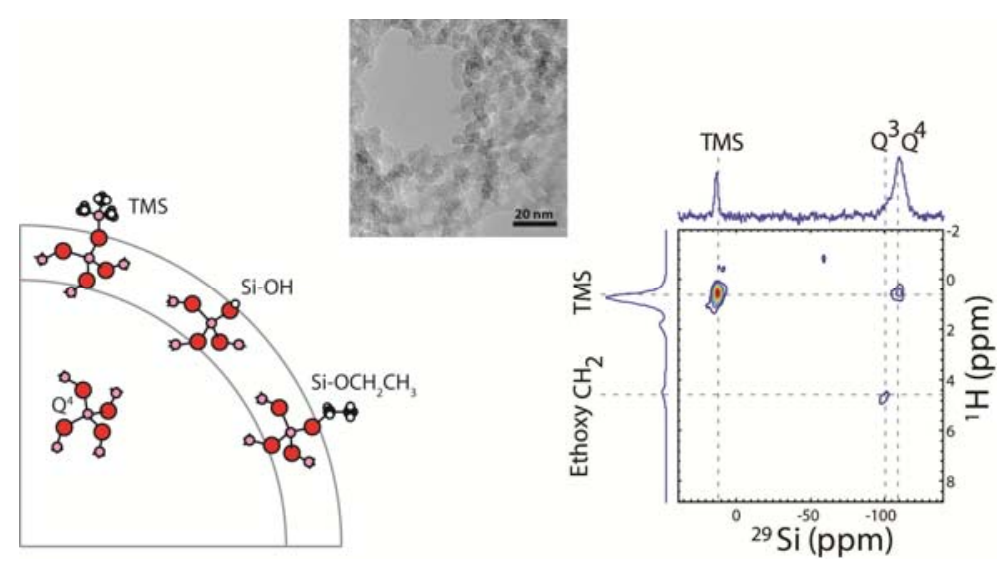

\section{REFERENCES}

(1) Kistler, S. S., Coherent Expanded Aerogels. J. Phys. Chem. 1932, 36, 52-64.

(2) Cuce, E.; Cuce, P. M.; Wood, C. J.; Riffat, S. B., Toward Aerogel Based Thermal Superinsulation in Buildings: a Comprehensive Review. Renew. Sust. Energ. Rev. 2014, 34, 273-299.

(3) Koebel, M. M.; Rigacci, A.; Achard, P., Aerogel-Based Thermal Superinsulation: an Overview. J. SolGel Sci. Tech. 2012, 63, 315-339.

(4) Pajonk, G. M., Aerogel Catalysts. Appl. Catal. 1991, 72, 217-266.

(5) Cui, S.; Cheng, W.; Shen, X.; Fan, M.; Russell, A.; Wu, Z.; Yi, X., Mesoporous Amine-Modified $\mathrm{SiO}_{2}$ Aerogel: a Potential $\mathrm{CO}_{2}$ Sorbent. Energ. Envir. Sci. 2011, 4, 2070-2074.

(6) Linneen, N. N.; Pfeffer, R.; Lin, Y. S., $\mathrm{CO}_{2}$ adsorption performance for amine grafted particulate silica aerogels. Chemical Engineering Journal 2014, 254, 190-197.

(7) Wörmeyer, K.; Alnaief, M.; Smirnova, I., Amino Functionalised Silica-Aerogels for $\mathrm{CO}_{2}$ Adsorption at Low Partial Pressure. Adsorption 2012, 18, 163-171.

(8) Smirnova, I.; Suttiruengwong, S.; Arlt, W., Feasibility Study of Hydrophilic and Hydrophobic Silica Aerogels as Drug Delivery Systems. Journal of Non-Crystalline Solids 2004, 350, 54-60.

(9) Reynolds, J. G.; Coronado, P. R.; Hrubesh, L. W., Hydrophobic Aerogels for Oil-Spill Cleanup Synthesis and Characterization. J. Non-Cryst. Solids 2001, 292, 127-137.

(10) Tewari, P. H.; Hunt, A. J.; Lofftus, K. D., Ambient-Temperature Supercritical Drying of Transparent Silica Aerogels. Mat. Lett. 1985, 3, 363-367.

(11) van Bommel, M. J.; de Haan, A. B., Drying of Silica Aergel with Supercritical Carbon Dioxide. J. Non-Cryst. Solids 1995, 186, 78-82. 
(12) Bhagat, S. D.; Oh, C.-S.; Kim, Y.-H.; Ahn, Y.-S.; Yeo, J.-G., Methyltrimethoxysilane Based Monolithic Silica Aerogels via Ambient Pressure Drying. Micropor. Mesopor. Mat. 2007, 100, 350-355.

(13) Prakash, S. S.; Brinker, C. J.; Hurd, A. J.; Raom, S. M., Silica Aerogel Fils Prepared at Ambient Pressure by Using Surface Derivatization to Induce Reversible Drying Shrinkage. Nature 1995, 374, 439-443.

(14) Rao, A. V.; Nislen, E.; Einarsrud, M.-A., Effect of Precursors, Methylation Agents and Solvents on the Physicochemical Properties of Silica Aerogels Prepared by Atmospheric Drying Method. J. NonCryst. Solids 2001, 296, 165-171.

(15) Shi, F.; Wang, L.; Liu, J., Synthesis and Characterization of Silica Aerogels by a Novel Fast Ambient Pressure Drying Process. Mat. Lett. 2006, 60, 3718-3722.

(16) Pajonk, G. M.; Elaloui, E.; Achard, P.; Chevalier, B.; Chevalier, J.-L.; Durant, M., Physical properties of silica gels and aerogels prepared with new polymeric precursors. Journal of Non-Crystalline Solids 1995, 186, 1-8.

(17) Rao, A. P.; Rao, A. V.; Pajonk, G. M., Hydrophobic and Physical Properties of the Two Step Processed Ambient Pressure Dried Silica Aerogels with Various Exchanging Solvents. Journal of Sol-Gel Science and Technology 2005, 36, 285-292.

(18) Wang, L.-J.; Zhao, S.-Y.; Yang, M., Structural Characteristics and Thermal Conductivity of Ambient Pressure Dried Silica Aerogels with One-Step Solvent Exchange/Surface Modification. Materials Chemistry and Physics 2009, 113, 485-490.

(19) Wong, J. C. H.; Kaymak, H.; Brunner, S.; Koebel, M. M., Mechanical Properties of Monolithic Silica Aerogels Made from Polyethoxydisiloxanes. Micropor. Mesopor. Mat. 2014, 183, $23-29$.

(20) Lee, C. J.; Kim, G. S.; Hyun, S. H., Synthesis of Silica Aerogels from Waterglass via New Modified Ambient Drying. Journal of Materials Science 2002, 37, (11), 2237-2241.

(21) Hæreid, S.; Nilsen, E.; Ranum, V.; Einarsrud, M.-A., Thermal and Temporal Aging of Two Step Acidbase Catalyzed Silica gels in Water/Ethanol Solutions. J. Sol-Gel Sci. Tech. 1997, 8, 153-157.

(22) Nadargi, D. Y.; Rao, A. V., Methyltriethoxysilane: New precursor for Synthesizing Silica Aerogels. Journal of Alloys and Compounds 2009, 467, (1-2), 397-404.

(23) Hayase, G.; Kanamori, K.; Nakanishi, K., New flexible aerogels and xerogels derived from methyltrimethoxysilane/dimethyldimethoxysilane co-precursors. Journal of Materials Chemistry 2011, 21, 17077.

(24) El Rassy, H.; Buisson, P.; Bouali, B.; Perrard, A.; Pierre, A. C., Surface Characterization of Silica Aerogels with Different Proportions of Hydrophobic Groups, Dried by the $\mathrm{CO}_{2}$ Supercritical Method. Langmuir 2003, 19, 358-363.

(25) El Rassy, H.; Pierre, A. C., NMR and IR Spectroscopy of Silica Aerogels with Different Hydrophobic Characteristics. J. Non-Cryst. Solids 2005, 351, 1603-1610.

(26) Sindorf, D. W.; Maciel, G. E., ${ }^{29}$ Si CP/MAS NMR Studies of Methylchlorosilane Reactions on Silica Gel. J. Am. Chem. Soc. 1981, 103, 4263-4265.

(27) Sindorf, D. W.; Maciel, G. E., Cross-Polarization/Magic-Angle-Spinning Silicon-29 Nuclear Magnetic Resonance Study of Silica Gel using Trimethylsilane Bonding as a Probe of Surface Geometry and Reactivity. J. Phys. Chem. 1982, 86, 5208-5219.

(28) Sindorf, D. W.; Maciel, G. E., Solid-State NMR Studies of the Reactions of Silica Surfaces with Polyfunctional Chloromethylsilanes and Ethoxymethylsilanes. J. Am. Chem. Soc. 1983, 105, 37673776.

(29) Sindorf, D. W.; Maciel, G. E., ${ }^{29}$ Si NMR study of Dehydrated/Rehydrated Silica Gel using Cross Polarization and Magic-Angle Spinning. J. Am. Chem. Soc. 1983, 105, 1487-1493.

(30) Halasz, I.; Kierys, A.; Goworek, J.; Liu, H.; Patterson, R. E., ${ }^{29}$ Si NMR and Raman Glimpses into the Molecular Structure of Acid and Base Set Silica Gels Obtained from TEOS and Na-silicate. J. Phys. Chem. C 2011, 115, 24788-24799. 
(31) Blümel, J., Reactions of Ethoxysilanes with Silica: a Solid-State NMR Study. J. Am. Chem. Soc. 1995, $117,2112-2113$.

(32) Hsieh, K.-Y.; Bendeif, E.-E.; Gansmuller, A.; Pillet, S.; Woike, T.; Schaniel, D., Structure and Dynamics of Guest Molecules Confined in a Mesoporous Silica Matrix: Complementary NMR and PDF Characaterization. RSC Adv. 2013, 3, 26132.

(33) Malfait, W. J.; Verel, R.; Koebel, M. M., Hydrophobization of Silica Aerogels: Insigths from Quantitative Solid-State NMR Spectroscopy. Journal of physical Chemistry C 2014, 118, 2554525554.

(34) Brunauer, S.; Emmett, P. H.; Teller, E., Adsorption of Gases in Multimolecular Layers. J. Am. Chem. Soc. 1938, 60, 309-319.

(35) Barrett, E. P.; Joyner, L. G.; Halenda, P. P., The Determination of Pore Volume and Area Distributions in Porous Substances. I. Computations from Nitrogen Isotherms. J. Am. Chem. Soc. 1951, 73, 373-380.

(36) Reichenauer, G., Structural Characterization of Aerogels. In Aerogels Handbook, Aegerter, M. A.; Leventis, N.; Koebel, M. M., Eds. Springer: New York, 2011; pp 449-498.

(37) van Beek, J. D., matNMR: a Flexible Toolbox for Processing, Analyzing and Visualizing Magnetic Resonance Data in Matlab. J. Magn. Reson. 2007, 187, 19-26.

(38) Malfait, W. J.; Halter, W. E.; Verel, R., ${ }^{29} \mathrm{Si}$ NMR spectroscopy of silica glass: T-1 relaxation and constraints on the Si-O-Si bond angle distribution. Chemical Geology 2008, 256, (3-4), 269-277.

(39) Apperley, D.; Hay, J. N.; Raval, H. M., Silica-Dimethyldisiloxane Hybrids - Non-Hydrolytic Sol-Gel Synthesis and Characterization by NMR Spectroscopy. Chem. Mat. 2002, 14, 983-988.

(40) Sakellariou, D.; Lesage, A.; Hodgkinson, P.; Emsley, L., Homonuclear Dipolar Decoupling in SolidState NMR using Continuous Phase Modulation. Chem. Phys. Lett. 2000, 319, 253-260.

(41) Mohite, D. P.; Larimore, Z. J.; Lu, H.; Mang, J. T.; C., S.-L.; Leventis, N., Monolithic Hierarchical Fractal Assemblies of Silica Nanoparticles Cross-Linked with Polynorbornene via ROMP: A StructureProperty Correlation from Molecular to Bulk through Nano. Chem. Mat. 2012, 24, 3434-3448.

(42) Kim, H. N.; Lee, S. K., Atomic Structure and Dehydration Mechanism of Amorphous Silica: Insights from ${ }^{29} \mathrm{SI}$ and ${ }^{1} \mathrm{H}$ Solid-State MAS NMR Study of $\mathrm{SiO}_{2}$ Nanoparticles. Geochim. Cosmochim. Acta 2013, 120, 39-64.

(43) Aegerter, M. A.; Leventis, N.; Koebel, M. M., Aerogels Handbook. Spriner-Verlag: New York, 2011. 